\title{
Transient stability enhancement of 30 bus multi- machine systems by using PSS \& increasing inertia
}

\author{
Nitin Mohan Lal, Arvind Kumar Singh \\ Electrical Engg. Deptt, B.I.T Sindri, Dhanbad, India \\ Email address: \\ nitinsumit009@gmail.com (N. M. Lal), singharvindk67@gmail.com (A. K. Singh)
}

\section{To cite this article:}

Nitin Mohan Lal, Arvind Kumar Singh. Transient Stability Enhancement of 30 Bus Multi- Machine Systems by using PSS \& Increasing Inertia. American Journal of Electrical Power and Energy Systems. Vol. 3, No. 2, 2014, pp. 21-26. doi: 10.11648/j.epes.20140302.12

\begin{abstract}
In this paper the transient stability enhancement of a 30- bus multi-machine system by using Power system stabilizer and increasing inertia has been observed, as single method is not sufficient for this purpose. We have created a three phase fault at time 0.04 seconds at bus 7 and cleared at time 0.5 seconds. On implementing PSS and on increasing the inertia of the machine we achieved a better response in terms of power swing when compared with initial condition. The inertia of the machine is kept within a certain limit. And 30 bus multi-machine system maintain its own permissible operating condition.
\end{abstract}

Keyword: Transient Stability, PSS, Inertia, Three Phase Fault

\section{Introduction}

Power system stability of modern large inter-connected systems is a major problem for secure operation of the system. Recent major black-outs across the world caused by system instability, even in very sophisticated and secure systems, illustrate the problems facing secure operation of power systems. Stability is defined as the ability of a system to return to its normal or stable operation after having been subjected to some form of disturbance.

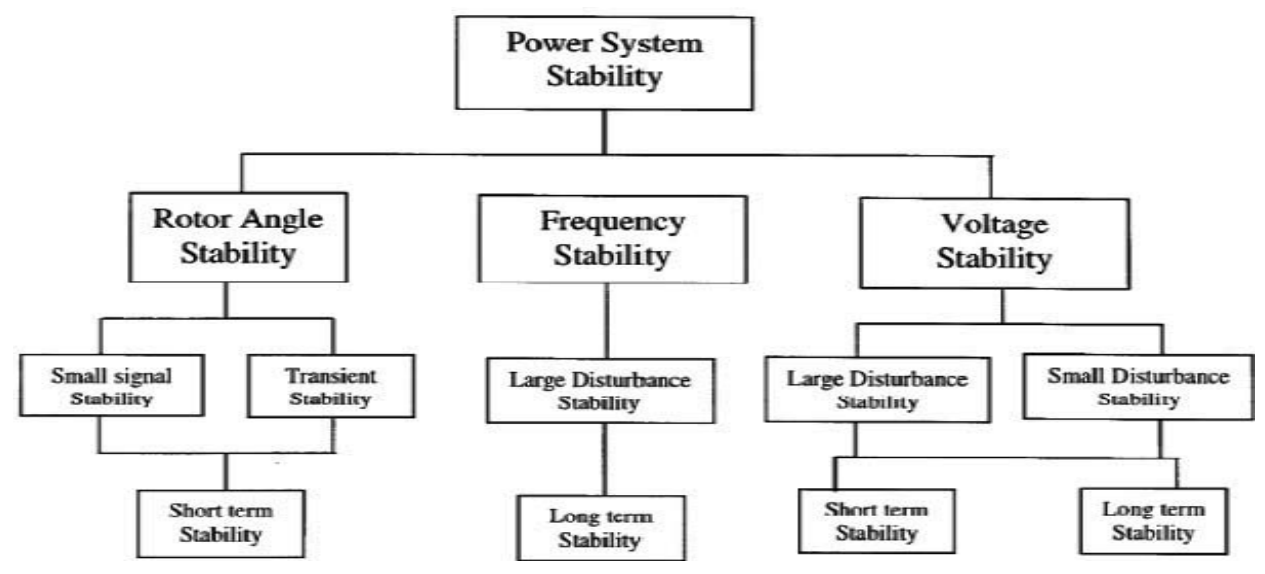

Figure 1. Classification of power system stability [1].

This mainly refers to the ability of the system to remain in synchronism. However, modern power systems operate under complex interconnections, controls and extremely stressed conditions. Further, with increased automation and use of electronic equipment, the quality of power has gained more importance, shifting focus on concepts of voltage stability, frequency stability, inter-area oscillations etc.

For the purpose of analysis the power system stability is sub divided into two major categories

i) Steady state stability. \&

ii) Transient stability. 
Steady-state stability refers to the ability of the power system to regain synchronism after small and slow disturbances, such as ground power changes. An extension of the steady-state stability is known as the dynamic stability. Transient stability studies deal with the effects of large, sudden disturbances, such as the occurrence of the fault, the sudden outage of a line

Transient stability of a power system is its ability to maintain synchronous operation of the machines when subjected to a large disturbance. The occurrence of such a disturbance may result in large excursions of the system machine rotor angles and, whenever corrective actions fail, loss of synchronism results among machines. Generally, the loss of synchronism develops in very few seconds after the disturbance inception.[2]

\subsection{Transient Stability Analysis}

The power system is almost regularly subjected to a variety of disturbances. Even the act of switching on an appliance in the house can be regarded as a disturbance. However, given the size of the system and the scale of the perturbation caused by the switching of an appliance in comparison to the size and capability of the interconnected system, the effects are not measurable. Large disturbance do occur on the system. These include severe lightning strikes, loss of transmission line carrying bulk power due to overloading. The ability of power system to survive the transition following a large disturbance and reach an acceptable operating condition is called transient stability.

Any disruption in the system will cause the imbalance between the mechanical power input to the generator and electrical power output of the generator to be affected. As a result, some of the generators will tend to speed up and some will tend to slow down. If, for a particular generator, this tendency is too great, it will no longer remain in synchronism with the rest of the system and will be automatically disconnected from the system. This phenomenon is referred to as a generator going out of step.

E-Tap allows the user to reduce very large and complex power systems into simple one line diagram and performs operations on it like load the system, subject the system to contingency and study the characteristics of faults. These virtual faults in the simulation model can be compared to the real time system faults.[15] In this paper enhancement of transient stability analysis of 30-bus multi machine system by using power system stabilizer (PSS), and increasing inertia is done. For this purpose we create a three phase fault on specified bus and then analyze the behaviour of the synchronous machine. For this work we have used the licensed version of ETAP software.

\subsection{Power System Stabilizer (PSS)}

Power system stabilizer provides an additional input signal to the regulator to damp power system oscillations. Some commonly used input signals are rotor speed deviation, accelerating power, and frequency deviation.[14]

The power system stabilizer uses auxiliary stabilizing signals to control the excitation system so as to improve power system dynamic performance this is very effective method of enhancing small signal stability performance.[3]. The main aim of the PSS is to provide damping with the help of a component of electrical torque in phase with the rotor speed variation, to the generator oscillation by using auxiliary stabilizing signal(s)[4].

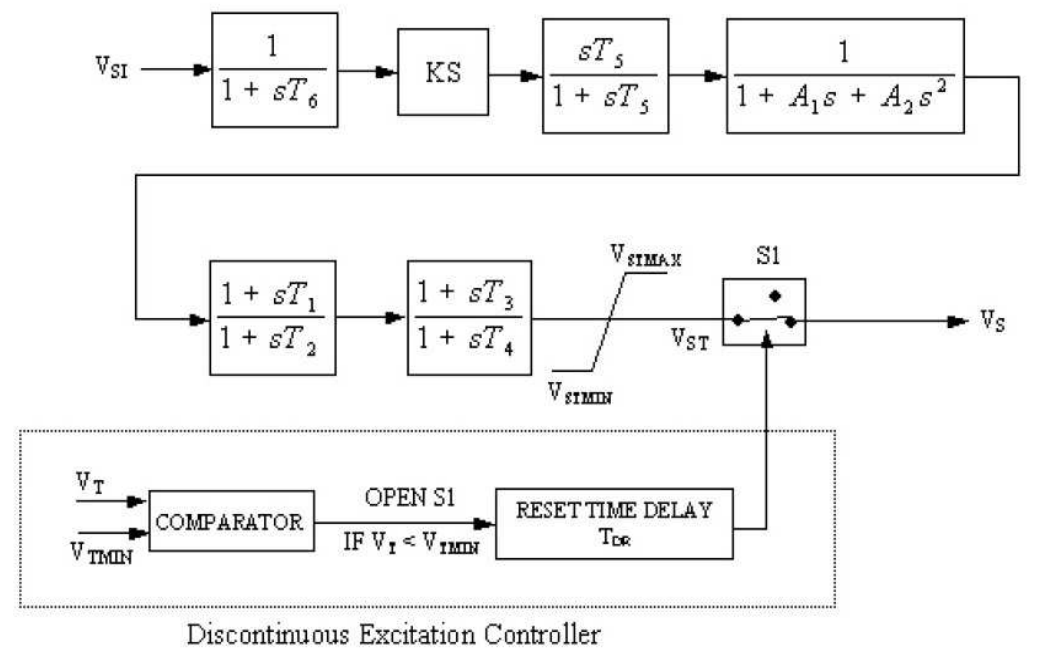

Figure 2. IEEE TYPE-1 PSS(PSS1A).

\section{Description of 30 Bus Model}

A 30 bus multi- machine system is taken here for the analysis purpose as shown in the figure. it consists of 30 bus , 6 generators, 4 transformers, 20 loads and 37 cables are connected in between the buses. 3 buses are in swing mode, 3 buses are voltage controlled bus and remaining 24 buses are load bus. The length of each cable is $50 \mathrm{~km}$ and positive, zero sequence component of impedance is $(0.015240+\mathrm{j} 0.027432)$ ohms per conductor per phase. The rating of generators, loads, PSS is given below in the following tables. 


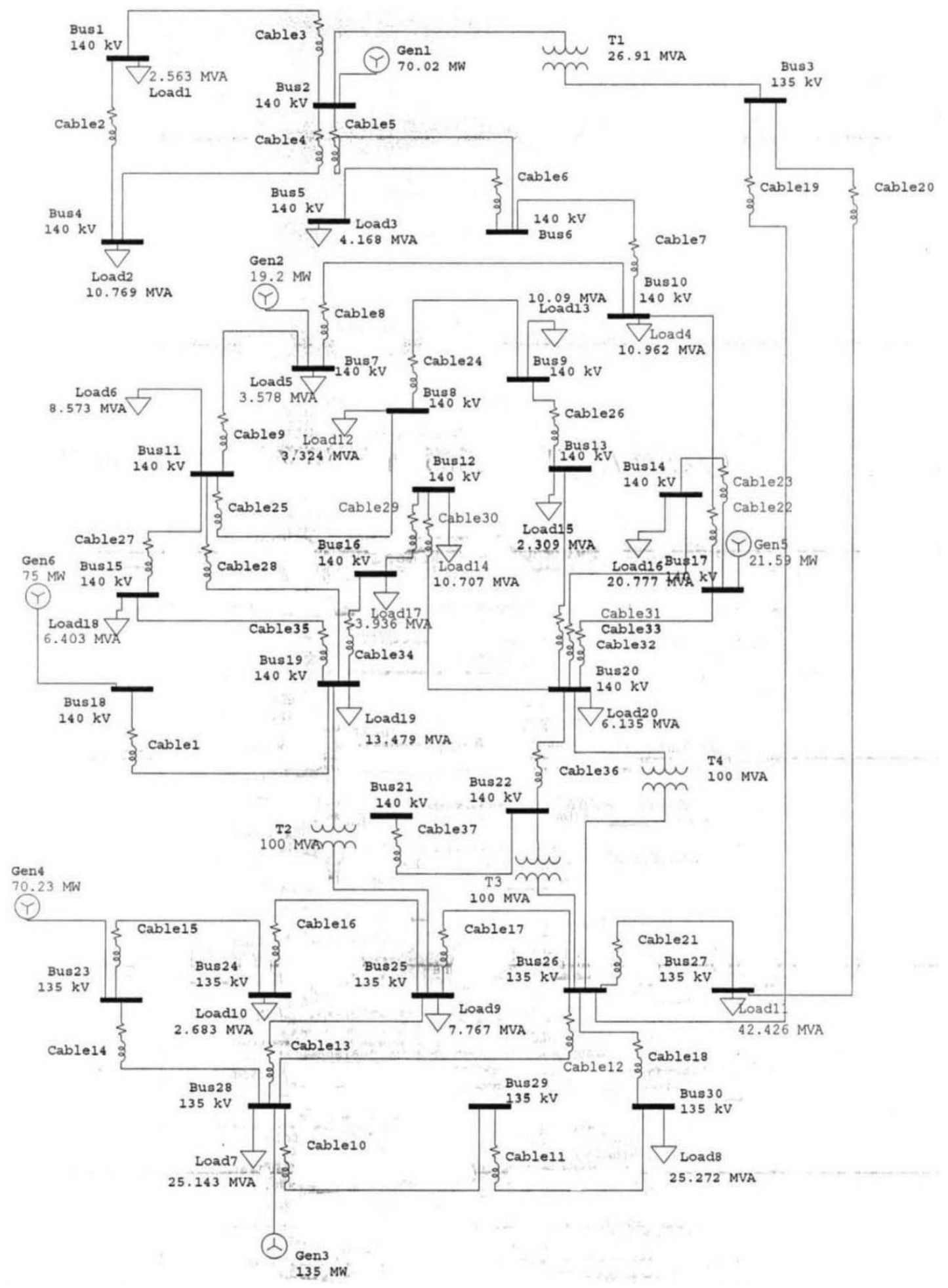

Figure 3. 30 Bus Test System.

\section{Result and Discussion}

In this paper we focus on the analysis of transient stability behaviour of a 30-bus multi machine system by implementing PSS and by increasing the inertia of the synchronous machine. For this purpose we have used
Accelerated gauss siedel method for initial load flow solution. The maximum number of iteration possible is 2000 , the solution precision for the initial load flow is 0.000001 , and the acceleration factor for the initial load flow is 1.45 . The time increment for integration steps $(\Delta t)$ is 0.01 and the system frequency is maintained at $50 \mathrm{~Hz}$.

The inertia of the synchronous machine is initially taken 
as $3 \mathrm{MW}-\mathrm{Sec} / \mathrm{MVA}$ and is increased later on to $7 \mathrm{MW}$ Sec/MVA for the analysis purpose. The inertia of a machine affects the bulkiness of the rotor of the machine; hence inertia cannot be increased much.

The 3-phase fault is created at bus 7 at time $0.04 \mathrm{sec}$ and is cleared after time $0.5 \mathrm{sec}$. the electromechanical oscillations of electrical power is reduced and field voltage is also kept limited, due to this reason excitation is maintained. The various plots of electrical power, field current, and terminal current individually initial, without PSS and with PSS and inertia combined respectively of generator 6 are as shown in figures.

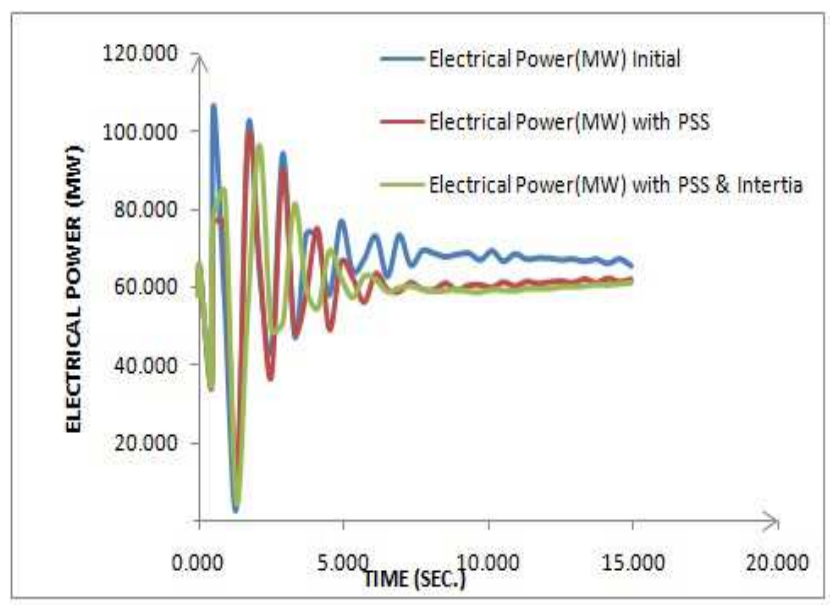

Figure 4. Electrical Power of Generator.

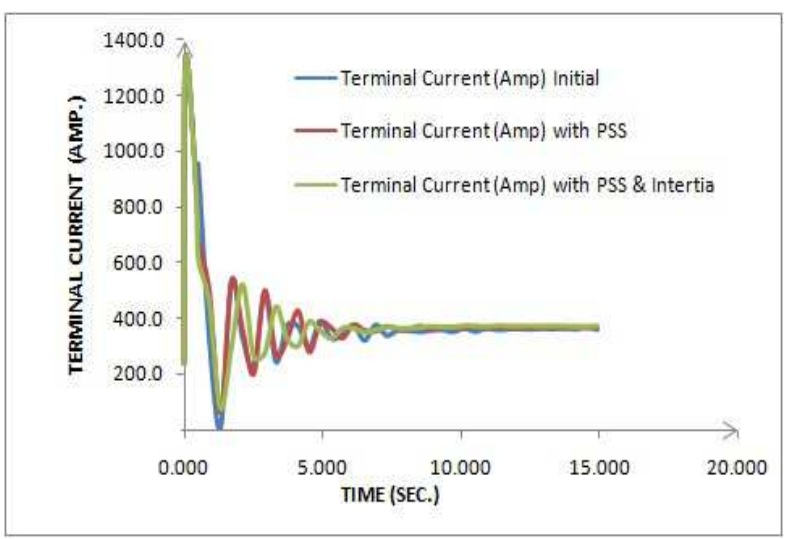

Figure 5. Terminal current of Generator 6.

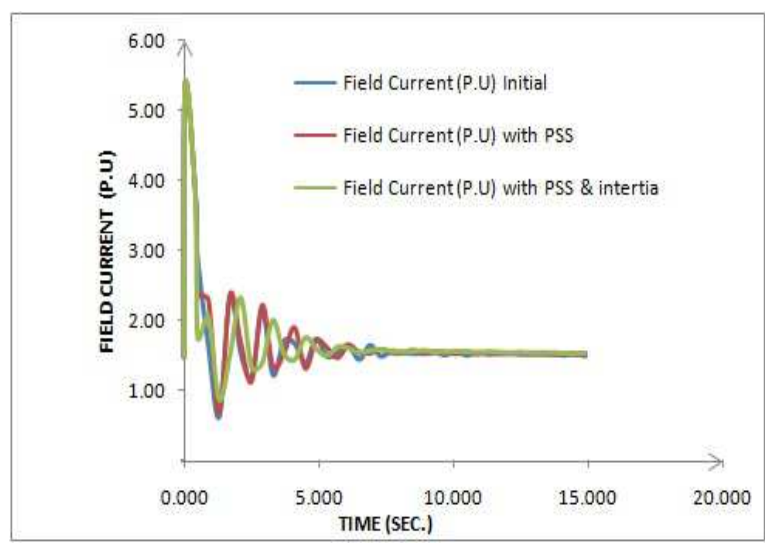

Figure 6. Field current of Generator 6.

Table 1. Synchronous machine parameters.

\begin{tabular}{|c|c|c|c|c|c|c|c|c|c|c|c|c|c|c|c|}
\hline \multicolumn{3}{|c|}{ Machine } & \multicolumn{2}{|l|}{ Rating } & \multicolumn{8}{|c|}{ Positive sequence impedence(\%) } & \multicolumn{3}{|c|}{ Zero seq. $Z(\%)$} \\
\hline ID & TYPE & MODEL & MVA & $\mathrm{KV}$ & $\mathrm{R}_{\mathrm{a}}$ & $X_{d}$ " & $X_{d}$, & $X_{d}$ & $\mathrm{X}_{\mathrm{q}}{ }^{\prime \prime}$ & $X_{q}^{\prime}$ & $X_{q}$ & $\mathrm{X}_{1}$ & $\mathrm{X} / \mathrm{R}$ & $\mathrm{R}_{0}$ & $\mathrm{X}_{0}$ \\
\hline Gen 1 & Generator & $\begin{array}{l}\text { Subtransient, } \\
\text { Round-Rotor }\end{array}$ & 82.376 & 140 & 1 & 19 & 28 & 155 & 19 & 65 & 155 & 15 & 7 & 1 & 7 \\
\hline Gen2 & Generator & $\begin{array}{l}\text { Subtransient, } \\
\text { Round-Rotor }\end{array}$ & 22.588 & 140 & 1 & 19 & 28 & 155 & 19 & 65 & 155 & 15 & 7 & 1 & 7 \\
\hline Gen3 & Generator & $\begin{array}{l}\text { Subtransient, } \\
\text { Round-Rotor }\end{array}$ & 158.824 & 135 & 1 & 19 & 28 & 155 & 19 & 65 & 155 & 15 & 7 & 1 & 7 \\
\hline Gen4 & Generator & $\begin{array}{l}\text { Subtransient, } \\
\text { Round-Rotor }\end{array}$ & 82.624 & 135 & 1 & 19 & 28 & 155 & 19 & 65 & 155 & 15 & 7 & 1 & 7 \\
\hline Gen5 & Generator & $\begin{array}{l}\text { Subtransient, } \\
\text { Round-Rotor }\end{array}$ & 25.4 & 140 & 1 & 19 & 28 & 155 & 19 & 65 & 155 & 15 & 7 & 1 & 7 \\
\hline Gen6 & Generator & $\begin{array}{l}\text { Subtransient, } \\
\text { Round-Rotor }\end{array}$ & 88.235 & 140 & 1 & 19 & 28 & 155 & 19 & 65 & 155 & 15 & 7 & 1 & 7 \\
\hline
\end{tabular}

Table 2. Dynamic parameters of Synchronous Machine.

\begin{tabular}{|c|c|c|c|c|c|c|c|c|c|c|c|c|}
\hline \multirow{2}{*}{$\begin{array}{l}\text { Machine } \\
\text { ID }\end{array}$} & \multirow{2}{*}{$\begin{array}{l}\text { Connected bus } \\
\text { ID }\end{array}$} & \multicolumn{4}{|c|}{ Time cons.(sec.) } & \multicolumn{5}{|c|}{ H(Sec.),,D(MW pu/Hz)\&Saturation } & \multicolumn{2}{|c|}{ Grounding } \\
\hline & & $\mathrm{T}_{\mathrm{d} 0} "$ & $\mathrm{~T}_{\mathrm{d} 0}$, & $\mathrm{T}_{\mathrm{q} 0} "$ & $\mathrm{~T}_{\mathrm{q} 0}$, & $\mathrm{H}$ & $\% \mathrm{D}$ & $\mathrm{S} 100$ & $\mathrm{~S} 120$ & Sbreak & Conn. & Type \\
\hline Gen 1 & Bus2 & 0.03 & 6.5 & 0.03 & 1.25 & 12 & 0 & 1.7 & 1.18 & 0.8 & WYE & SOLID \\
\hline Gen2 & Bus7 & 0.03 & 6.5 & 0.03 & 1.25 & 12 & 0 & 1.7 & 1.18 & 0.8 & WYE & SOLID \\
\hline Gen3 & Bus28 & 0.03 & 6.5 & 0.03 & 1.25 & 12 & 0 & 1.7 & 1.18 & 0.8 & WYE & SOLID \\
\hline Gen4 & Bus23 & 0.03 & 6.5 & 0.03 & 1.25 & 12 & 0 & 1.7 & 1.18 & 0.8 & WYE & SOLID \\
\hline Gen5 & Bus17 & 0.03 & 6.5 & 0.03 & 1.25 & 12 & 0 & 1.7 & 1.18 & 0.8 & WYE & SOLID \\
\hline Gen6 & Bus18 & 0.03 & 6.5 & 0.03 & 1.25 & 12 & 0 & 1.7 & 1.18 & 0.8 & WYE & SOLID \\
\hline
\end{tabular}


Table 3. Mechanical parameters of synchronous machine.

\begin{tabular}{|c|c|c|c|c|c|c|c|c|c|c|c|c|c|}
\hline \multirow{2}{*}{$\begin{array}{l}\text { Machine } \\
\text { ID }\end{array}$} & \multirow[b]{2}{*}{ TYPE } & \multicolumn{3}{|c|}{ Generator/Motor } & \multicolumn{3}{|l|}{ Coupling } & \multicolumn{3}{|c|}{ Prime Mover/Load } & \multicolumn{3}{|c|}{ Equivalent Total } \\
\hline & & $\mathbf{W R}^{2}$ & RPM & $\mathbf{H}$ & $\mathbf{W R}^{2}$ & RPM & $\mathbf{H}$ & $\mathbf{W R}^{2}$ & RPM & $\mathbf{H}$ & $\mathbf{W R}^{2}$ & RPM & $\mathbf{H}$ \\
\hline Gen 1 & Gen. & 475476.97 & 1500 & 3 & 330193 & 1800 & 3 & 330193 & 1800 & 3 & 1426432.75 & 1500 & 9 \\
\hline Gen2 & Gen. & 13379 & 1500 & 3 & 90541 & 1800 & 3 & 90541 & 1800 & 3 & 391137.09 & 1500 & 9 \\
\hline Gen3 & Gen. & 916730 & 1500 & 3 & 636618 & 1800 & 3 & 636618 & 1800 & 3 & 2750189.75 & 1500 & 9 \\
\hline Gen4 & Gen. & 476904 & 1500 & 3 & 331183 & 1800 & 3 & 331183 & 1800 & 3 & 1430711 & 1500 & 9 \\
\hline Gen5 & Gen. & 146609 & 1500 & 3 & 101812 & 1800 & 3 & 101812 & 1800 & 3 & 439827.56 & 1500 & 9 \\
\hline Gen6 & Gen. & 509295 & 1500 & 3 & 353677 & 1800 & 3 & 353677 & 1800 & 3 & 1527884.75 & 1500 & 9 \\
\hline
\end{tabular}

$\mathrm{WR}^{2}: \mathrm{kg}-\mathrm{m}^{2} \quad \mathrm{H}: \mathrm{MW}-\mathrm{Sec} / \mathrm{MVA}$

Table 4. POWER SYSTEM STABILIZER (PSS) INPUT DATA Type: PSSIA.

\begin{tabular}{lllllllllllllll}
\hline Generator ID & VSI & KS & VSTMax & VSTMin & VTMin & TDR & A1 & A2 & T1 & T2 & T3 & T4 & T5 & T6 \\
\hline Gen 1 & SPEED & 3.15 & 0.9 & -0.9 & 0 & 0.2 & 0 & 0 & 0.76 & 0.1 & 0.76 & 0.1 & 1 & 0.1 \\
Gen 2 & SPEED & 3.15 & 0.9 & -0.9 & 0 & 0.2 & 0 & 0 & 0.76 & 0.1 & 0.76 & 0.1 & 1 & 0.1 \\
Gen 3 & SPEED & 3.15 & 0.9 & -0.9 & 0 & 0.2 & 0 & 0 & 0.76 & 0.1 & 0.76 & 0.1 & 1 & 0.1 \\
Gen 4 & SPEED & 3.15 & 0.9 & -0.9 & 0 & 0.2 & 0 & 0 & 0.76 & 0.1 & 0.76 & 0.1 & 1 & 0.1 \\
Gen 5 & SPEED & 3.15 & 0.9 & -0.9 & 0 & 0.2 & 0 & 0 & 0.76 & 0.1 & 0.76 & 0.1 & 1 & 0.1 \\
Gen 6 & SPEED & 3.15 & 0.9 & -0.9 & 0 & 0.2 & 0 & 0 & 0.76 & 0.1 & 0.76 & 0.1 & 1 & 0.1 \\
\hline
\end{tabular}

Table 5. LOAD RATING

\begin{tabular}{cc}
\hline LOAD & RATING (MVA) \\
\hline 1 & 02.563 \\
2 & 10.769 \\
3 & 04.168 \\
4 & 10.962 \\
5 & 03.578 \\
6 & 08.573 \\
7 & 25.143 \\
8 & 25.272 \\
9 & 07.767 \\
10 & 02.683 \\
11 & 42.426 \\
12 & 03.324 \\
13 & 10.090 \\
14 & 10.707 \\
15 & 02.309 \\
16 & 20.777 \\
17 & 03.936 \\
18 & 06.403 \\
19 & 13.479 \\
20 & 06.135 \\
\hline
\end{tabular}

\section{Conclusion}

The paper presents the improved behaviour of transient stability of a 30-bus multi machine system when implemented with PSS and when inertia is increased, using E-TAP software. The comparison of transient stability performances of the multi machine system initial, with PSS, and with PSS and inertia combined is performed and found that the power swing is damped out, and we get better response in terms of electromechanical oscillations.

\section{References}

[1] Farmer, Richard G. "Power System Dynamics and Stability", The Electric Power Engineering Handbook, Ed. L.L. Grigsby,Boca Raton: CRC Press LLC, 2001.
[2] TRANSIENT STABILITY OF POWER SYSTEMS A Unified Approach to Assessment and Control Mania PAVELLA, Damien ERNST, Research Fellow, FNRS Daniel RUIZVEGA University of Li 'ege, Belgium Kluwer Academic Publishers Boston/Dordrecht/London

[3] prabha kundur, power system stability and control, tata McGraw Hill publication,edition 2011

[4] Bablesh Kumar Jha, Ramjee Prasad Gupta, Upendra Prasad. Combined Operation of SVC, PSS and Increasing Inertia of Machine for Power System Transient Stability Enhancement. American Journal of Electrical Power and Energy Systems. Vol. 3, No. 1, 2014, pp. 7-14. doi: $10.11648 /$ j.epes.20140301.12

[5] W.Watson and G.Manchur, "Experience with supplementary Damping Signals for Generator Static ExicationSystem,'IEEE Trans.,Vol.PAS-92,pp. 199203,January/February 1973

[6] W.Watson and M.E Coultes ,"Static Exicter Stabilizing Signals on Large Generators-Mechanical Problems,"IEEE Trans.,Vol. PAS-92,pp.204 211,January/February 1973

[7] P.Kundur ,D.C.Lee and H.M. Zein EL-Din,"Power system stabilizer fot thermal units:Analytical Techniques and OnSite Validation,'JEEE Trans.,Vol.PAS-100,pp. 8195,January 1981

[8] M.L. Shelton, R.F Winklemen, W.A Mittelstandt, and W.L Bellerby,"Bonneville Power Administration 1400 MW Braking Resistor,'IEEE Trans.,VOL.PAS 94,pp.602611,March/april 1975

[9] P.K. Iyambo, R. Tzonova, "Transient Stability Analysis of the IEEE 14-Bus Electrical Power System", IEEE Conf. 2007

[10] N. Mo, Z.Y. Zou, K.W. Chan, T.Y.G. Pong, “Transient stability constrained optimal power flow using particleswarm optimization", IET Generation, Transmission \& Distribution, Vol. 1, pp. 476-483, 2007

[11] D. Chatterjee, A. Ghosh, "Transient Stability Assessment of PowerSystems Containing Series and Shunt Compensators," IEEE Trans. onpower systems, vol. 22, no. 3, August 2007 

using PSS \& Increasing Inertia

[12] IEEJ Technical Committee, Standard models of power system, IEEJ Technical Report, Vol. 754, 1999

[13] P. M. Anderson and A. A. Fouad. Power System Control and Stability.The IEEE Press, 1995.
[14] Electric Systems, Dynamics, and Stability with Artificial Intelligence ... By James A. Momoh, Mohamed E. ElHawary,copyright@2000 by Marcel Dekker Inc.

[15] Kavitha R, "Transient stability of IEEE-30 bus system using E-TAP software,’IJSER, vol.3,issue 12,December 2012 